\section{The Future of Work under Global Restructuring} Results of the European Project
WORKS

\author{
by Bettina-Johanna Krings, ITAS
}

\begin{abstract}
Anyone who wants to understand globalisation in everyday life should have a look on the manifold changes of work. However, changes of work can only be fully understood in the context of a global restructuring of value chains, where sectors, organisations, labour processes and skills simultaneously change their patterns and structures. However, from the European perspective, there is a considerable heterogeneity with regard to skill supply, levels of employment and welfare systems. In a fouryear research programme, the EU-project WORKS (Work Organisation Restructuring in the Knowledge Society) has investigated major changes of work in the context of economic globalisation.
\end{abstract}

\section{Introduction}

The project WORKS was funded within the $6^{\text {th }}$ Framework Programme of the European Commission in 2005. Under the coordination of the Higher Institute for Labour Studies (HIVA, Catholic University of Leuven) in Belgium, the WORKS consortium brought together partners from 17 institutions from fourteen EU Member States. One of the underlying assumptions of the WORKS project is the global context of value chains. Disentangling causes and effects of these processes and identifying the drivers of change seems to be very difficult, but on the other side it is of great importance to understand the factors that enable companies to sustain their competitive edge and to ensure future employment. To understand these effects it is necessary to examine the effects not only on the quality of work but also on the quality of life, i.e. the work-life balance. At the heart of the project the question is raised: How does employment adjust to changes and with what effects? Based on an ambitious programme of theoretical and empirical work, the project results offer an insight into different trends and considerations which will be pointed out in the following sections.

\section{Design and course of the project ${ }^{1}$}

Basically, the design of the WORKS project is based on five main pillars: "theories and concepts", "quantitative research", "policy", "qualitative research on organisation" and "qualitative research on individuals".

In the first stage of the project, the WORKS partners collectively carried out a review of the large body of literature relevant to the project's research questions in order to map the field, formulate hypotheses and develop a clear conceptual framework for the research. Under supervision of Ursula Huws from the London Metropolitan University, a report was written with expertise from a wide range of theoretical perspectives and academic disciplines. The report reviews academic evidence on the sociology of work, economic geography, organisational theory, social psychology, ethnography, gender studies, industrial relations, and political science. This evidence was carefully sifted with the aim of distilling insights that could help to produce a clear conceptual framework for the project's empirical work but also serve as a guideline of the research concept. Consequently, the report is organised along the main research topics of the project (restructuring of value chains, policy and social dialogue, new forms of work organisation, etc.) and provides an overview of the academic debates within these topics. The report was published in 2006 and provides not only for the project a remarkable and valuable overview of the key drivers and effects of changes of work in Europe (Huws 2006).

In the second stage of the project, quantitative and qualitative research was carried out simultaneously by different partners in different work packages. The quantitative research pillar analysed the changes of work in Europe on the basis of comparative analyses of data from existing European organisation and individual/household surveys. In a first step, major European surveys were mapped and benchmarked in order to assess their relevance and their strengths and weaknesses for comparative analyses on changes of work. A thematic analysis of 13 major 
national and international organisation surveys was summarised in an overview report, focusing on the main results on the key issues of the project and including a wide range of topics (Ramioul, Huys 2007). Three major sources of individual and household data were used to carry out a longitudinal and EU-wide comparative analysis on the issues relevant for the WORKS project: the Community Labour Force Survey (CLFS), the European Working Conditions Survey (EWCS), and the European Community Household Panel (ECHP). Four reports were published, each focusing on the identification of trends with respect to key issues of the project: (1) Tracing Employment in Business Functions: A Sectoral and Occupational Approach (Geurts et al. 2007); (2) Trends in Work Organisation and Working Conditions (Greenan et al. 2007); (3) Work Flexibility in Europe (Birindilli, Rusticelli 2007); (4) Occupational Change in Europe (Brynin, Longhi 2007).

The qualitative research pillar was divided into qualitative research on organisations and qualitative research on individuals. Both types covered a number of generic business functions that represent a wide variety of activities and labour processes in knowledge-based societies, ranging from highly skilled knowledge work to semi-skilled manual tasks. The selected business functions were: software development, research and development, design, costumer services in the public sector and in logistics, production work in the food and clothing industry. The selection of sectors and branches reflects the emergence of global value chains in different historical stages: sectors where vertical disintegration and internationalisation have already some tradition and sectors where these have developed only recently.

Each business function in a particular sector was studied in a range of countries with diverse employment and welfare regimes. Overall, 58 organisation cases studies were conducted in 13 countries (for a synthesis report see Flecker et al. 2007). These case studies were completed by 30 case studies investigating the impacts of changes of work on individuals and their households (for a synthesis report see Valenduc et al. 2007).

The policy pillar plays a crucial role, particularly for EU projects. In the WORKS project, issues of policy and social dialogue were considered by examining the effects of policy initiatives and regulation on work organisation and work life at national and international level. A special focus was on the role of institutions in the determination, implementation and enforcement of restructuring policy. A further issue was the role of workers' representatives in tempering the effects at the workplace resulting from this restructuring, including the terms and conditions of employment, fragmentation and segmentation, gender equality, training and skilling, and quality of working life (Meil et al. 2006).

\section{Future trends of work in Europe ${ }^{2}$}

As the different research pillars show, a wide range of research activities have been carried out in the WORKS project over the last four years. Both the quantitative and qualitative research have yielded a diversity of results which should be considered in the context of the specific research questions.

However, in view of the thematic consistency of the results within the different pillars it is possible to identify future trends of work at a superordinate level. Corporate restructuring will increasingly take place in nearly all branches and sectors with tremendous effects on the working conditions as well as on the work-life balance. One of the key characteristics of off-shoring and outsourcing is the fact that different business activities are decomposed, fragmented and recomposed in different organisational forms, both contractually and spatially. As the results clearly show, the process of corporate fragmentation is not only a strong tendency in the manufacturing sector but also in the service industry and in public services. But there are also processes of insourcing and geographical and organisational consolidation taking place to strengthen overall control over the global value chain and improve the competitive position of the firm within the chain.

When analysing the key drivers of value chain restructuring, a variety of drivers was considered. In some sectors, such as clothing, the ongoing shortened innovation cycles of collections were crucial aspects for value chain restructuring. In other sectors like food or IT, mergers and acquisitions and growing interna- 
tionalisation were the triggers for company restructuring. Less surprisingly, cost reduction is still the prime motive for relocation of production activities. This refers specifically to the privatisation process, which has been the most common transformation process in public services in recent years (Huws et al. 2009). Thus, accelerating business processes, shortening time horizons, heterogeneity of products and services, cost reduction, and a strong orientation towards the market are important requirements in all sectors, branches and organisations.

The employment impact of these processes seems remarkable. Although the processes are heterogeneous across occupational groups, it can be concluded that, in general, value chain restructuring may be an additional trigger for the flexibilisation of the work force. This basically refers to an increased use of flexible contracts and flexible working times. Some current changes indicating future employment trends in Europe can be highlighted here:

1. Higher levels of contingent and precarious work can be found at the bottom of the value chain.

2. The most comprehensive effects of value chain restructuring observed in the case studies are increased temporal pressure, resulting from an increased impact of costumers, time zone differences, increased market pressures, and acceleration of businesses. Quantitative work also experiences an increase in temporary work, shift work and part-time work in most countries.

3. A striking finding is that there is an increase in the fragmentation of employment conditions both across and within firms. For instance, in IT service provision, which has shown a strong trend towards internationalisation and lengthening of value chains, the workforce, formerly employed under the same contracts, is increasingly fragmented, with different terms and conditions. Across the branches reviewed, there is a general trend that relocated activities are regulated according to the norms, rules and practices at the destination. The increasing implementation of employment regulations and institutional context of the destination country also affects the working conditions in other units of the chain. In a large number of interviews with individuals confronted with restructur- ing, feelings of insecurity were systematically reported, even in cases were the actual employment status in a strict legal sense was not precarious.

4. With regard to skills and qualification under global restructuring, it seems that the workers need more skills in order to be able to respond to speeding-up processes as well as to new forms of the global division of labour. The increasing fragmentation of work has various effects. On the one hand, core professional skills, i.e. communication and social skills, become more important, which has already led to significant changes in job profiles. On the other hand, a high proportion of the European workforce feels overqualified for the work they do. This is especially true for people with fixed-term contracts or in casual work.

5. The impact of global restructuring on working conditions and work-life balance is remarkable. As already mentioned above, the results of the qualitative research show that processes on a global scale lead to a high level of insecurity and the feeling of powerlessness by the workers (especially in low qualified jobs). In addition to the requirement of temporal and contractual flexibility, these feelings have a tremendous impact on the work-life balance of many people. The study clearly shows that female workers in many countries have to face disadvantages in this context.

\section{WORKS at ITAS}

Within the WORKS consortium, the ITAS team was involved in the theoretical and conceptual work as well as in the qualitative research of the project. Besides conducting several case studies at organisational and occupational level, the ITAS team, together with the Fondation Travail-Université (FTU) in Namur, Belgium, was leading the comparative and synthesising work on all occupational case studies (Valenduc et al. 2007). In order to avoid a thousand pages report, the final report of the project was divided into several thematic issues. The ITAS team, together with the Instituti di Ricerche Economiche e Sociali (IRES) in Rome, Italy, elaborated the thematic report 
"Working time, gender, work-life balance" (Krings et al., forthcoming).

The EU-project is part of the ITAS research activity "Technologies and their impact on work", which belongs to the research field "Knowledge Society and Knowledge Policy" of the ITAS research portfolio. To foster the scientific debate on changes of work in European knowledge societies, ITAS organised an international workshop with the support of the WORKS consortium. The workshop was held at the end of May 2009.

The project enriches and intensifies the tradition of ITAS' research activities in the field and opens the view for the global perspective which has already been the subject of several publications. The overall results, however, indicate that it is necessary to be very much aware of the effects of global restructuring as they are likely to affect large parts of work but also everyday life. This will probably be an important scientific issue in the near future.

\section{Notes}

1) The design and course of the project was described by Ursula Huws for all thematic reports. In this summary, I took over some parts of her description. Therefore, I would like to thank Ursula Huws from the London Metropolitan University for her detailed and summarising work in the project.

2) The overall results have been summarised by the coordinator of the WORKS project Monique Ramioul, HIVA Leuven, in many presentations and have been published in: Enterprise and Work Innovation Studies (IET) 4 (2008), S. 9-19. Large parts of this publication are taken over in this article.

\section{References}

Birindilli, L.; Rusticelli, E., 2007: The Transformation of Work? Work Flexibility in Europe: A Sectoral and Occupational Description of Trends in Working Hours, Part-time Work, Temporary Work, and Self-employment. WORKS report, Leuven

Brynin; M.; Longhi, S, 2007: The Transformation of Work? Occupational Change in Europe. WORKS report, Leuven

Flecker, J.; Holtgrewe, U.; Schönauer, A. et al., 2007: Restructuring Across Value Chains and Changes in Work and Employment. Case study evidence from the Clothing, Food, IT and Public Sector. WP 10 Organisational Case Studies - Synthesis Report, Leuven

Geurts, C.; Coppin, L.; Ramioul, M., 2007: The Transformation of Work? Tracing Employment in Business Functions. A sectoral and occupational approach. WORKS report, Leuven

Greenan, N.; Kalugina, E.; Walkowiak, E., 2007: The Transformation of Work? Trends in Work Organisation. WORKS report, Leuven

Huws, U. (ed.), 2006: The Transformation of Work in a Global Knowledge Economy: Towards a Conceptual Framework. Leuven

Huws, U.; Dahlmann, S.; Flecker, J. et al. (forthcoming): Value Chain Restructuring in Europe in a Global Economy. Leuven

Krings, B.-J.; Nierling, L.; Pedaci, M. et al. (forthcoming): Working Time, Gender, Work-life Balance. Leuven

Ramioul, M.; Huys, R., 2007: Comparative Analysis of Organisation Surveys in Europe. Literature Review of Secondary Analysis. WORKS report, Leuven Meil, P.; Trommel, W.; Bannink, D. et al., 2006: Comparative Report. WP5, Policy Pillar, Leuven Valenduc, G.; Vendramin, P.; Krings, B.-J. et al., 2007: Occupational Case Studies. Synthesis Report and Comparative Analysis. WP 11, Leuven

\section{Contact}

M.A. Bettina-Johanna Krings

Forschungszentrum Karlsruhe ITAS

P.O. Box 36 40, 76021 Karlsruhe Phone: +49 (0) 7247 / 82 - 6347

Email: krings@itas.fzk.de

\section{$《 》$}

